\title{
Density Gradient Centrifugation
}

National Cancer Institute

\section{Source}

National Cancer Institute. Density Gradient Centrifugation. NCI Thesaurus. Code C16411.

A method of separating macromolecules by either their differential rate of sedimentation in a centrifug al gradient or their differential buoyancy in a density gradient. (from biologytext.com) 